\title{
Genes diferencialmente expressos em cana-de-açúcar inoculada com Xanthomonas albilineans, o agente causal da escaldadura da folha
}

\author{
Karina Maia Dabbas ${ }^{1}$, Maria Inês Tiraboschi Ferro ${ }^{1}$, Neli Martins de Barros ${ }^{1}$, Marcelo Luiz de Laia ${ }^{1}$, Sonia Marli \\ Zingaretti ${ }^{1}$, Poliana Fernanda Giachetto ${ }^{1}$, Vicente Alberto de Moraes $^{2}$, Jesus Aparecido Ferro ${ }^{1 *}$
}

\begin{abstract}
1 *Universidade Estadual Paulista - UNESP. Faculdade de Ciências Agrárias e Veterinárias de Jaboticabal, Departamento de Tecnologia, Via de Acesso Prof. Paulo Donato Castellane, km 5 - CEP: 14884-900, Jaboticabal-SP.; ${ }^{2}$ Centro de Tecnologia Canavieira (CTC),Piracicaba, SP. Autor para correspondência: Email: mitferro@fcav.unesp.br Parte da Dissertação de mestrado do primeiro autor, apresentada à FCAV-UNESP. Bolsista da FAPESP Data de chegada: 22/01/2004. Aceito para publicação em: 10/11/2005.
\end{abstract}

\begin{abstract}
Dabbas, K.M.; Ferro, M.I.T.; Barros, N.M.; Laia, M.L.; Zingaretti, S.M.; Giachetto, P.F.; Moraes, V.A.; Ferro, J.A. Diferential gene expression in sugar cane infected with Xanthomonas albilineans, causal agent of leaf scald. Summa Phytopathologica, v.32, n.4, p.328-338, 2006.

The leaf scald disease, caused by the xylem-invading pathogen Xanthomonas albilineans, is one of the most devastating diseases of sugarcane. Chronic symptoms are characterized by white pencil-line streaks surrounding invaded leaf vascular bundles, which may result in fully burnt leaves, and by lateral bud development. In this work, using a macroarray approach, we analyzed the expression profile of 3,575 ESTs (expressed sequence tags) of sugarcane, in two sugarcane varieties, classified as susceptible (SP78-4467) or resistant (SP82-1176) to Xanthomonas albilineans infection. Membranes were constructed with ESTs from sugarcane leaf roll tissues and hybridized with radio labeled

cDNAs from infected and non-infected sugarcane tissue. Data analysis showed a different pattern of expression during pathogen infection. This approach allowed the identification of differentially induced ESTs for proteins involved isoprenoid biosynthesis, transmembrane LRR protein, leucine zipper, lignification, cold tolerance, plant response and environmental adaptation in the resistant variety. Repressed ESTs in this variety were related to proteins involved in plant cellular expansion, detoxification, and auxin transport. In the susceptible variety, the differentially repressed ESTs were related to proteins involved in plant defense response, Ethylene biosynthesis, and transcription regulation.
\end{abstract}

Additional keywords: cDNA, resistence genes, avirulence genes, host-pathogen interaction, macroarray.

\section{RESUMO}

Dabbas, K.M.; Ferro, M.I.T.; Barros, N.M.; Laia, M.L.; Zingaretti, S.M.; Giachetto, P.F.; Moraes, V.A.; Ferro, J.A. Genes diferencialemtne expressos em cana-de-açúcar inoculada com Xanthomonas albilineans, o agente causal da escaldadura da folha. Summa Phytopathologica, v.32, n.4, p.328-338, 2006.

A escaldadura da folha, causada pela bactéria Xanthomonas albilineans colonizadora do xilema, é uma das principais doenças da cana-de-açúcar. A sintomatologia na fase crônica é caracterizada principalmente pelo aparecimento de uma faixa branca paralela à nervura central da folha, que evolui até queimar totalmente, sendo também observado brotação de gemas laterais no colmo. Neste trabalho, a técnica de macroarranjos de cDNA foi empregada para o estudo da expressão de 3.575 ESTs (espressed sequence tags) em folhas de cana-de-açúcar. Foram utilizadas duas variedades, uma resistente (SP82-1176) e outra suscetível (SP78-4467) a Xanthomonas albilineans as quais foram infectadas mecanicamente por ferimentos. As membranas dos macroarranjos foram confeccionadas a partir de ESTs de bibliotecas de folha e cartucho de cana-de-açúcar provenientes do projeto SUCEST e hibridizadas contra sondas de cDNA de plantas infectadas e controle marcadas com isótopos radioativos. Analisando os resultados dos macroarranjos foi possível verificar um comportamento diferenciado para cada variedade durante o ataque do patógeno. Após realizadas análises estatísticas identificamos na variedade resistente ESTs com expressão induzida relacionadas com biossíntese de isoprenoides, proteínas LRR transmembrânica, "ziper" de leucina, lignificação, tolerância ao frio, diferenciação de plastídeos, sistemas de defesa e de adaptação da planta ao meio ambiente. As ESTs reprimidas na variedade resistente foram àquelas relacionadas com genes responsáveis pela síntese de proteínas do controle da expansão da parede celular, detoxificação e transporte de auxina. Na variedade susceptível foram reprimidas ESTs relacionadas a genes de proteínas das respostas de defesa da planta, biossíntese de Etileno e regulação da transcrição.

Palavras-chave adicionais: cDNA, genes de resistência, genes de avirulência, interação planta-patógeno, macroarranjos. 


\section{INTRODUÇÃO}

A escaldadura da folha é uma das principais doenças que acometem a cultura de cana-de-açúcar em vários países. O agente causal, Xanthomonas albilineans, é uma bactéria Gram-negativa, sistêmica, que se desenvolve no xilema (5). Essa fitobactéria é responsável pela produção de uma família de antibióticos e fitotoxinas chamadas albicidinas, que inibem a replicação de DNA em organismos procarióticos, atuando como agente bactericida para uma gama de bactérias Gram-negativas e Gram-positivas (6). As albicidinas inibem também a replicação do DNA em proplastídeos de cana-de-açúcar, ocasionando a clorose típica da doença (5).

A sintomatologia inicial da escaldadura, apresentada por plantas suscetíveis, é caracterizada pelo aparecimento de uma faixa branca (clorótica), de aproximadamente 1-2 $\mathrm{mm}$, que acompanha a nervura central da folha, evoluindo para o murchamento, necrose e morte da planta, sendo observado também, em alguns casos, o multibrotamento de gemas laterais (33).

A disseminação da doença ocorre no plantio de colmos infectados e durante o corte da cultura por meio da utilização de facões ou implementos agrícolas contaminados com exsudatos de plantas doentes. A grande dificuldade no controle da doença está no fato de que ela pode ocorrer também na forma de infecção latente, difícil de diagnosticar, pois os sintomas podem ser transientes ou mesmo ausentes em cultivares resistentes (33). Assim, vários métodos foram desenvolvidos com o objetivo de diagnosticar a infecção latente, incluindo métodos sorológicos, tais como microaglutinaçao, ELISA e pela técnica de PCR (10).

Atualmente, as estratégias de controle da doença se restringem à troca de variedades suscetíveis por variedades resistentes e no plantio de mudas sadias. Assim, variedades com características agronônicas desejáveis e com alto potencial de produção, mas que são suscetíveis à doença, são descartadas durante o processo de seleção de novas variedades comerciais. Nestes casos, a introdução de genes, por engenharia genética, que conferissem resistência à $X$. albilineans, seria uma estratégia que poderia permitir o aproveitamento deste material.

Nas interações planta-patógeno, para que ocorra a ativação do sistema de defesa da planta é necessário o reconhecimento de determinantes de avirulência pelos receptores da planta (26). No patossistema cana-Xanthomonas albilineans ainda não está elucidado o mecanismo que confere resistência a algumas variedades de cana, não havendo relatos na literatura a respeito de receptores na cana relacionados à família de toxinas de albicidina produzida por esta fitobactéria. As fitotoxinas de albicidina parecem desempenhar um papel importante no desenvolvimento sistêmico da doença, visto que mutantes de $X$. albilineans que não produzem albicidinas (mutantes tox-), gerados por mutagênese usando luz UV, agentes químicos ou transposon, são incapazes de produzir qualquer sintoma da doença quando inoculados em cana-de-açúcar (7).

Dentro desse contexto, o estudo do perfil de expressão diferencial de genes em variedades de cana-de-açúcar resistente e suscetível a escaldadura pode permitir um maior entendimento a respeito da relação planta-patógeno, representando uma valiosa fonte de informações que poderão ser utilizadas em estudos de mapeamento de genes de resistência.

No presente trabalho, utilizou-se membranas de náilon de alta densidade (macroarranjo), para analisar a expressão diferencial de 3.575 sequências de etiquetas expressas (ESTs) em variedades de cana-deaçúcar resistente e suscetível à escaldadura da folha, quando infectadas por $X$. albilineans.

\section{MATERIAL E MÉTODOS}

\section{Ensaio experimental}

As variedades comerciais de cana-de-açúcar são híbridos interespecíficos de Saccharum $s p$. As variedades SP82-1176 (resistente) e SP78-4467 (suscetível) são utilizadas como padrão de resistência e suscetibilidade à $X$. albilineans, respectivamente, pelo CTC (Centro de Tecnologia Canavieira). Plantas destas duas variedades foram utilizadas como controle em um experimento de campo planejado para determinar o nível de resistência à $X$. albilineans de vários clones em processo de seleção. $O$ experimento foi conduzido no CTC seguindo delineamento experimental de blocos casualizados. Para as duas variedades foram plantados colmos infectados e não infectados com a bactéria, sendo posteriormente coletadas folhas com e sem sintomas de cada uma delas.

O ensaio de macroarranjo constituiu-se da hibridação de quatro membranas de náilon com quatro preparações independentes de cDNA foliar obtido da variedade resistente inoculada e não inoculada e da variedade suscetível inoculada (com sintomas) e não-inoculada (sem sintomas), com três repetições cada uma. Em ambas as variedades, resistente (SP82-1176) e suscetível (SP78-4467), a expressão gênica apresentada por plantas inoculadas $\operatorname{com} X$. albilineans foi contrastada com a expressão gênica de plantas não inoculadas (controle).

\section{Inoculação}

A inoculação das duas variedades de cana-de-açúcar com $X$. albilineans foi realizada através de corte dos colmos, no sulco de plantio, com facão contaminado com uma solução de caldo de canade-açúcar contendo a bactéria. O caldo com a bactéria foi obtido pela trituração e prensagem de colmos com sintomas de escaldadura (conjunto de variedades). Este é o método comumente utilizado para a obtenção de suspensão viável de $X$. albilineans em experimentos de infecção simulando o que eventualmente acontece no plantio normal (36).

\section{Confirmação da infecção}

A confirmação da infecção das plantas pela bactéria foi realizada por observação dos sintomas característicos da doença, tais como faixa clorótica acompanhando a nervura central das folhas, emissão de brotações laterais e pela análise do fluido extraído do xilema de amostras aleatórias de colmos da touceira. Os testes sorológicos para confirmação da presença da bactéria foram realizados com $100 \mu \mathrm{L}$ de seiva, obtidas por centriguação dos colmos e, posteriormente transferidas para membrana de nitrocelulose $(0,45 \mu \mathrm{m})$ e em seguida colocada em contado com antisoro de coelhos imunizados com $X$. albilineans (dados não mostrados).

\section{Extração de RNA}

Após 5 meses do plantio foi realizada a coleta de amostras de tecido foliar, as quais foram armazenadas em freezer $-80^{\circ} \mathrm{C}$ até o momento da extração do RNA.

O RNA total foi isolado de folhas de cana-de-açúcar, incluindo as nervuras, utilizando solução monofásica de fenol e isotiocianato de guanidina. Três gramas de tecido foram macerados em $\mathrm{N}_{2}$ líquido e homogeneizados em $15 \mathrm{~mL}$ de Trizol (Life Tecnologies) em tubos de centrífuga de vidro (Corex) de $30 \mathrm{~mL}$. As amostras foram incubadas por cinco minutos à temperatura ambiente $\left(23^{\circ} \mathrm{C}\right)$. Foram adicionados $0,2 \mathrm{~mL}$ de clorofórmio para cada $1 \mathrm{~mL}$ do reagente Trizol e, então, as amostras foram agitadas vigorosamente em vortex e incubadas por 3 minutos à temperatura ambiente. As amostras foram centrifugadas a 
$7.500 \mathrm{x} g$ por 15 minutos, a $4^{\circ} \mathrm{C} . \mathrm{O}$ sobrenadante foi transferido para um tubo Corex de $15 \mathrm{~mL}$ e o RNA foi precipitado pela adição de 0,5 $\mathrm{mL}$ de álcool 2-propanol para cada $1 \mathrm{~mL}$ de reagente Trizol usado na homogeneização inicial. A mistura foi mantida à temperatura ambiente por 10 minutos e depois centrifugada a $12.000 \mathrm{x} g$ por igual período, a $4^{\circ} \mathrm{C}$. O precipitado foi lavado com etanol $75 \%(1 \mathrm{~mL}$ de etanol para cada $1 \mathrm{~mL}$ de reagente Trizol utilizado na homogeneização inicial). As amostras foram agitadas vigorosamente em vortex e centrifugadas à $7.500 \mathrm{x} g$ por 5 minutos. O precipitado de RNA foi dissolvido em 100 $\mu \mathrm{L}$ de água livre de RNAse (água tratada com dietilpirocarboneto) e armazenado à $80^{\circ} \mathrm{C}$.

A quantificação do RNA extraído foi feita em biofotômetro (Eppendorf), na diluição de 1:10 (v/v). As medidas de absorbância foram realizadas nos comprimentos de onda de 260 e $280 \mathrm{~nm}$, utilizando-se água/DEPC para o ajuste inicial do aparelho. A qualidade do RNA foi analisada por eletroforese em gel de agarose 1,5\% (p/v) contendo $6,7 \%$ de formaldeído $(\mathrm{v} / \mathrm{v})$.

\section{Preparação de membranas para macroarranjo}

Para a preparação das membranas de alta densidade foi utilizado DNA plasmidial de 3.575 clones ESTs provenientes de bibliotecas de cDNA construídas pelo SUCEST (http://www.lbi.ic.unicamp.br/) (45) a partir de mRNA de folhas e de cartucho de cana-de-açúcar. O DNA plasmidial dos clones ESTs foi obtidos por meio de micro-preparação realizada através de lise alcalina em placas de 96 poços. Todos os clones foram re-sequenciados para confirmar a identidade do inserto.

As 3.575 amostras de DNA plasmidial foram transferidas para membranas de náilon de $85 \times 125 \mathrm{~mm}$, carregadas positivamente (Genetix), utilizando-se um sistema robotizado (Q-BOT-GENETIXUK) presente no Centro Brasileiro de Estocagem de Genes (BCCCenter - http://www.bcccenter.fcav.unesp.br). As amostras foram depositadas em duplicata, com espaçamento de 900 micras entre cada ponto, num arranjo $5 \mathrm{X} 4$, perfazendo um total de 7.152 ESTs por membrana. Após a transferência do DNA, as membranas foram submetidas a tratamento em solução de desnaturação $(\mathrm{NaCl} 1,5 \mathrm{M} \mathrm{e}$ $\mathrm{NaOH} 0,5 \mathrm{M})$ e de neutralização $(\mathrm{NaCl} 1,5 \mathrm{M}$ e Trizma $1 \mathrm{M})$ por 5 e 10 min., respectivamente e, posteriormente, fixou-se o DNA à membrana por radiação com luz UV (1600 joules) em aparelho Ultraviolet Crosslinker (CL1000, UVP), seguindo as recomendações do fabricante (Genetix, UK).

\section{Hibridações}

\section{Síntese da sonda de cDNA}

Em um tubo de microcentrífuga, foram adicionados: $30 \mu \mathrm{g}$ de RNA total e 156 pmoles de Oligo dT ( $\mathrm{dT}_{18} \mathrm{VN}$, Invitrogen), perfazendo um volume final de $7,5 \mu \mathrm{L}$. A mistura foi aquecida a $75^{\circ} \mathrm{C}$ durante 10 minutos e, em seguida, colocada em gelo. Foram adicionados à reação: $5 \mu \mathrm{L}$ de tampão de primeira fita (5x, BRL), 2,5 $\mu \mathrm{L}$ DTT (100mM), $2,0 \mu \mathrm{L}$ RNAguard, $2,5 \mu \mathrm{L}$ dNTPs (ATG) $10 \mathrm{mM}$ cada e $3 \mu \mathrm{L}$ de $[\alpha-$ $\left.{ }^{33} \mathrm{P}\right] \mathrm{dCTP}(30 \mu \mathrm{Ci})$. A mistura foi aquecida a $42^{\circ} \mathrm{C}$ por 5 minutos, e então adicionou-se 1,25 $\mu \mathrm{L}$ da enzima Superscript II (BRL, 200U/ $\mu \mathrm{L}$ ), prosseguindo-se com rápida centrifugação em microcentrífuga e incubação a $42^{\circ} \mathrm{C}$ por 30 minutos. Um volume de $1,25 \mu \mathrm{L}$ de dCTP $(10 \mathrm{mM})$ foi adicionado à reação e esta foi incubada a $42^{\circ} \mathrm{C}$ durante 60 minutos. Após esse período foi adicionado $1 \mu \mathrm{L}$ de Poly-A $(2 \mu \mathrm{g} / \mu \mathrm{L}$, Invitrogen) e, em seguida, a sonda foi desnaturada a $94{ }^{\circ} \mathrm{C}$ durante 5 minutos. Acrescentou-se então $1,4 \mu \mathrm{L}$ de $\mathrm{NaOH} 5 \mathrm{M}$ e incubou-se a $37{ }^{\circ} \mathrm{C}$ durante 15 minutos. Ao final desse período foram acrescentados $1,8 \mu \mathrm{L}$ de $\mathrm{HCl} 3,94 \mathrm{M}$ e $7,0 \mu \mathrm{L}$ de Tris-HCl $1 \mathrm{M} \mathrm{pH} 7,5$, e o volume final foi ajustado para $50 \mu \mathrm{L}$ com água MilliQ.
A sonda foi purificada em coluna de Sephadex G-50 equilibrada com STE e montada em uma seringa de $1 \mathrm{~mL}$ contendo lã de vidro siliconizada em sua extremidade inferior (37). Através de centrifugação a $4.000 \mathrm{rpm}$ (centrífuga clínica) por 4 minutos, o volume eluído da coluna foi recuperado em microtubo de 1,5 mL. Em seguida foram adicionados $100 \mu \mathrm{L}$ de STE à coluna e, após nova centrifugação, o volume eluído foi novamente coletado e misturado com o obtido anteriormente (39).

Pré-hibridação e hibridação de membranas de alta densidade

As hibridações foram feitas seguindo o protocolo descrito por McPherson (28); (http://www.tree.caltech.edu/protocols/ overgo.html). Para diminuir o background, as membranas foram colocadas inicialmente em solução fervente de SDS 0,1\%, seguindo as recomendações do fabricante.

Tanto as hibridações como as lavagens foram feitas em um forno de hibridação Hybaid, modelo H9360 (Hybaid Instruments, Holbrook, NY). As membranas foram colocadas em solução de pré-hibridação em garrafas de vidro com tampa $(15 \times 3,5 \mathrm{~cm})$, por $4 \mathrm{~h}$ na primeira vez que foram utilizadas e por $2 \mathrm{~h}$ nas vezes seguintes, a $58^{\circ} \mathrm{C}$, utilizandose um volume de $10 \mathrm{~mL}$ da solução por membrana. A solução de préhibridação foi a mesma utilizada na hibridação (1\% BSA, 7\% SDS, $0,5 \%$ tampão fosfato de sódio $1 \mathrm{M}$ ).

Após a purificação e desnaturação da sonda a $95^{\circ} \mathrm{C}$ por 5 minutos, esta foi adicionada à solução de hibridação no cilindro contendo as membranas e o conjunto permaneceu por $18 \mathrm{~h}$ a $58^{\circ} \mathrm{C}$, quando então foram lavadas.

\section{Lavagem das membranas}

Após a hibridação, procedeu-se a lavagem das membranas para retirada do excesso de sonda e das hibridações inespecíficas que possivelmente tenham ocorrido. As membranas foram lavadas três vezes, por períodos de 30 minutos a $58^{\circ} \mathrm{C}$, de maneira sucessiva, com aproximadamente $100 \mathrm{~mL}$ das seguintes soluções: $2 \mathrm{xSSC}+$ $0,1 \%$ SDS $; 1,5 \mathrm{xSSC}+0,1 \%$ SDS e $0,5 \mathrm{xSSC}+0,1 \%$ SDS. Após a última lavagem as membranas foram removidas da solução, seladas entre dois plásticos e colocados em cassete contendo uma placa com material sensível à radioatividade (Image Plate, Fujifilm), onde permaneceram por um período de $96 \mathrm{~h}$, após o qual a captação da imagem digitalizada foi adquirida através de um leitor fósforo radioativo (Phosphoimager FLA3000-G-Fujifilm, Tokyo) aclopado a um microcomputador.

\section{Remoção da sonda}

Cada membrana foi hibridada três vezes com sondas preparadas de maneira independente. Para a remoção da sonda, após cada hibridação, cada membrana foi lavada duas vezes em $100 \mathrm{~mL}$ de solução $0,4 \mathrm{NaOH}+0,1 \%$ SDS por 15 minutos a $65^{\circ} \mathrm{C}$ seguida por duas lavagens por 15 minutos à temperatura ambiente com uma solução de $0,1 \% \mathrm{SDS}+0,1 \% \mathrm{SSC}+0,2 \mathrm{~N}$ Tris- $\mathrm{HCl}$. As membranas foram seladas e colocadas novamente no cassetes por $96 \mathrm{~h}$. A eficiência da remoção da sonda foi monitorada repetindo-se o processo de leitura do fósforo radioativo (FLA3000-G-Fujifilm, Tokyo).

\section{Análise dos macroarranjos}

Os sinais obtidos das imagens foram quantificados usando-se o software "Array Vision" (Imaging Research, St. Catherines, ON, Canada). A mediana do valor da emissão de fundo local ("background") foi subtraída automaticamente da intensidade de cada ponto, de modo a se ter a intensidade real de cada amostra (sVol). Os dados relativos à 
emissão de fundo para cada ponto, a emissão bruta dos pontos e a diferença entre eles foram exportados para uma planilha do programa MS Excel (Microsoft, Redmond, WA).

\section{Análises Estatísticas}

As análises estatísticas foram conduzidas com o auxílio do programa estatístico R (R Development Core Team, 2003) e de aplicações desenvolvidas especialmente para análises estatísticas de dados obtidos a partir da técnica de "DNA arrays" (Bioconductor - http:// www.bioconductor.org/). A normalização dos dados foi executada com o auxílio de pacotes vsn (14) e os genes diferencialmente expressos foram identificados por meio da biblioteca limma (40). Em ambos os casos as configurações padrões foram mantidas, tanto para as normalizações quanto para a obtenção dos genes diferencialmente expressos.

As duas duplicatas em cada arranjo foram utilizadas para maximizar a medida da expressão diferencial de cada gene por meio da função lmFit dentro do pacote Limma (40). Esta etapa utiliza uma estimativa da correlação entre as duplicatas para gerar uma estimativa mais robusta da expressão do gene, comparando a média aritmética das duplicatas. A expressão diferencial dos genes foi determinada usando uma função empírica de Bayes (EB) dentro do pacote Limma (40), a qual calcula um $t$ estatístico moderado, com base nos erros padronizados, para cada gene. Após a análise EB, os genes diferencialmente expressos foram organizados de forma descendente segundo o valor do Bestatístico ("log-odds" da expressão diferencial) (40). Nenhum valor de significância foi especificado por este tipo de análise, sendo que os níveis de aceitação ou de rejeição de um gene como sendo diferencialmente expresso foi determinado empiricamente, após análises gráficas do tipo volcano, o qual permite que se possa observar quando os genes selecionados estão bem separados da nuvem de dados (46). Além desse item, considerou-se, também, o P value associado a cada EST, também calculado por meio da análise EB, e o B-estatístico. A freqüência de descobertas falsas (FDR), um método proposto por Benjamini \& Hochberg (3) e definido como a proporção de descobertas falsas, foi empregado nas análises (40). Neste estudo, padronizou-se estudar os 100 primeiros ESTs diferencialmente expressos em cada ensaio biológico (variedade suscetível não inoculada versus inoculada e variedade resistente não inoculada versus inoculada).

\section{RESULTADOS E DISCUSSÃO}

As marcações visíveis nas imagens digitalizadas das membranas (Figura 1), geradas pela hibridação das mesmas com as sondas de cDNA oriundos das duas variedades de cana-de-açúcar, SP82-1176 (resistente) e SP78-4467 (suscetível), foram transformadas em valores numéricos associados, os quais foram inicialmente normalizados a fim de diminuir a influência de erros experimentais (Figura 2).

Após a realização das análises estatísticas, 100 ESTs de cada variedade foram selecionadas e as seqüências submetidas aos bancos de dados do NCBI (http://www.ncbi.nlm.nih.gov/blast) para identificação da proteína codificada (Blastx). A categoria funcional de cada proteína foi então verificada utilizando-se o banco de dados SwissProt (http://ca.expasy.org), após o que as proteínas foram classificadas e agrupadas de acordo com as categorias funcionais propostas pelo The Institute for Genomic Research (TIGR). Encontrou-se proteínas pertencentes às seguintes categorias funcionais: expressão gênica, metabolismo, estrutura celular, proteínas nucleares, proteínas transportadoras, proteína sem classificação definida, proteína hipotética conservada e proteína desconhecida (Figura 3). Aquelas proteínas presentes em outros organismos e cuja função não pode ser determinada por meio de análise em banco de dados foram agrupadas como proteínas hipotéticas conservadas e aquelas que não tiveram homologia com nenhuma seqüência em banco de dados foram agrupadas como proteínas desconhecidas. Dos 100 genes selecionados como diferencialmente expressos para a variedade resistente, 53 apresentaram-se induzidos enquanto que 47 apresentaram-se reprimidos (Figura 4). Na variedade suscetível no entanto, 33 genes foram induzidos e 67 foram reprimidos (Figura 4). A Figura 5 mostra a dispersão gráfica de cada um dos genes selecionados conforme a sua expressão diferencial. Em ambos os casos os genes apresentaram valores de mudança de nível de expressão ( $\log _{2}$ Fold Change) maior que 2 para os genes induzidos e menor que -2 para os genes reprimidos.

$\mathrm{Na}$ variedade resistente, apresentou-se induzida uma EST com similaridade à proteína relacionada com a biossíntese de isoprenóide (LR1055F02, e-value: 7.e-05, gi:29367407), que em plantas superiores participa de uma ampla variedade de funções biológicas, tais como fotossíntese, respiração, crescimento, controle do ciclo celular, defesa da planta e adaptação às condições ambientais. Exemplos específicos
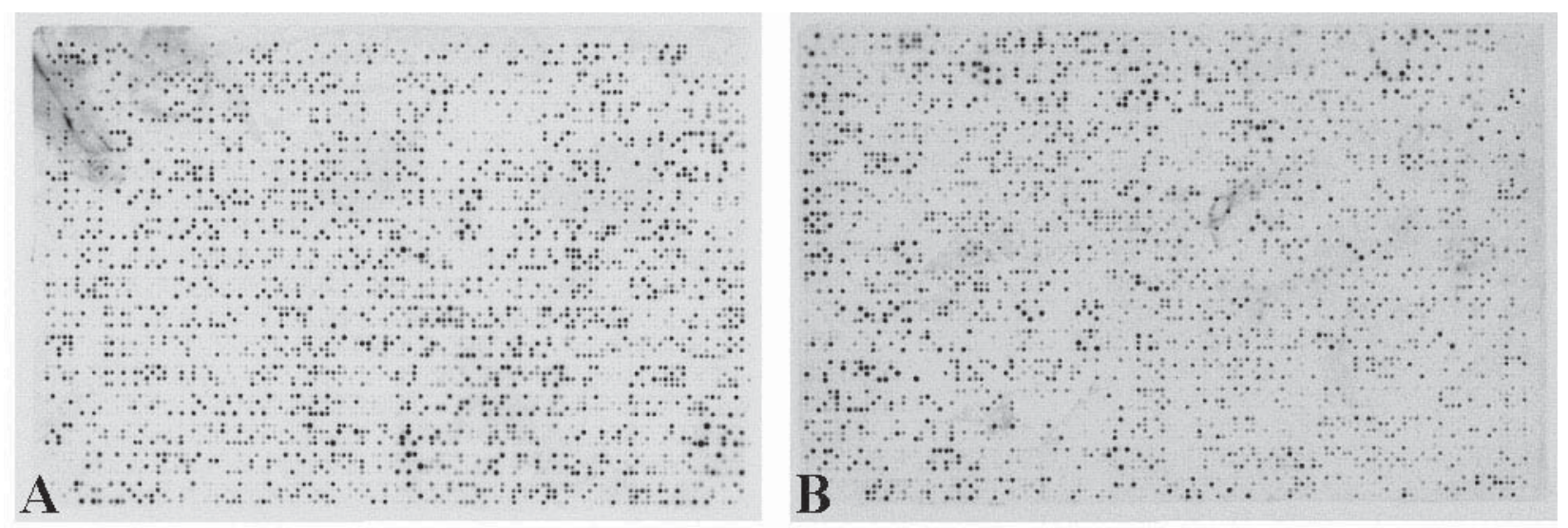

Figura 1: Imagem digitalizada de um dos quatro conjuntos de membranas de náilon $(85 \times 125 \mathrm{~cm})$ contendo 3.575 ESTs em duplicata, que foram utilizados para analisar a expressão gênica de cana-de-açúcar infectada com $X$. albilineans. As membranas foram hibridizadas com [ $\left.\alpha{ }^{-33} \mathrm{P}\right] \mathrm{cDNA}$ produzido por ação da transcriptase reversa sobre $30 \mu \mathrm{g}$ de RNA total de folha de cana-de-açúcar. (A) Hibridização com cDNA da variedade SP78-4467, suscetível à escaldadura da folha, não inoculada (controle); (B) Hibridização com cDNA da variedade SP78-4467, suscetível à escaldadura da folha, após 5 meses da inoculação com X. albilineans. 

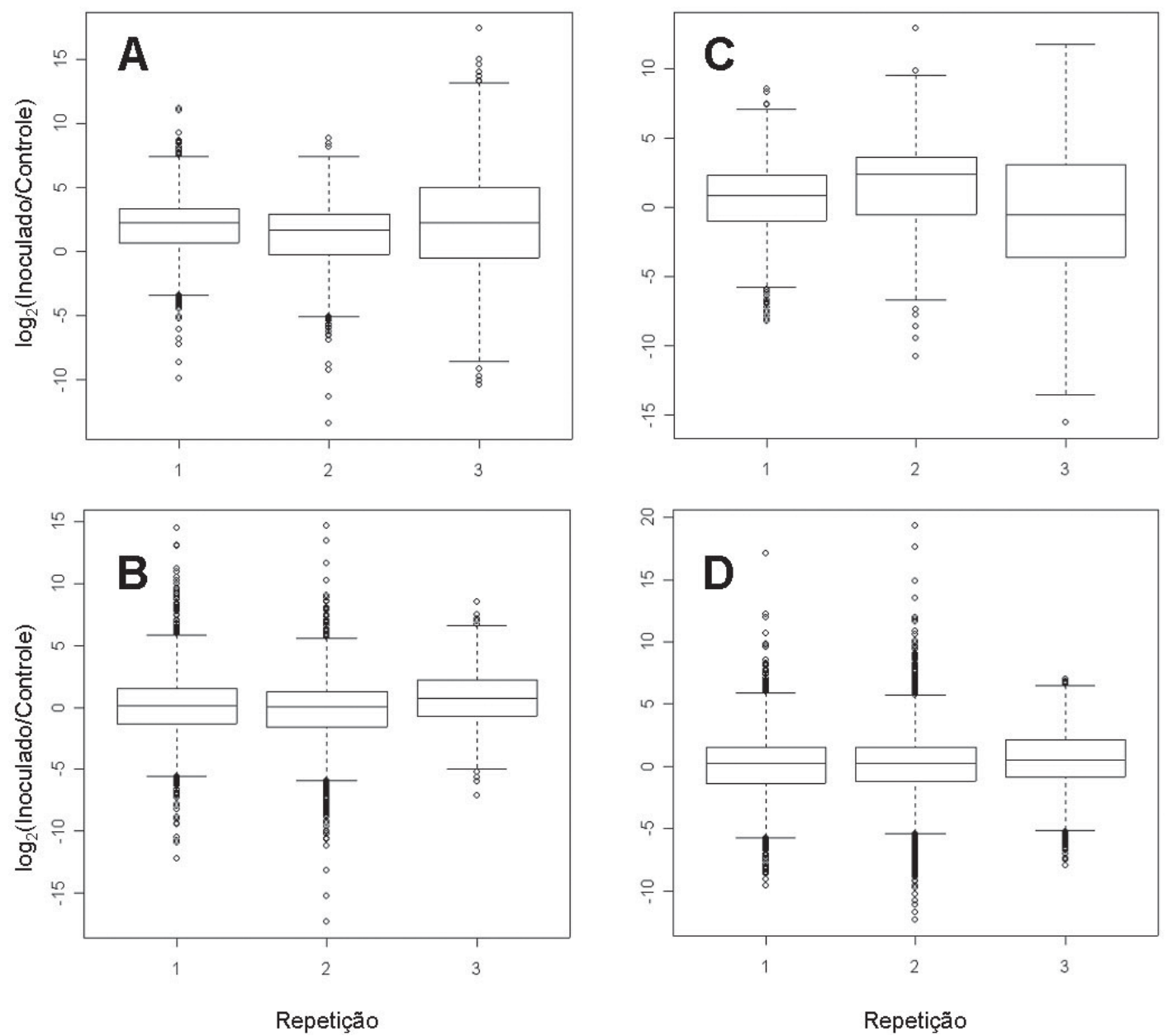

Figura 2. Representação gráfica dos dados de expressão diferencial obtidos para as membranas, antes (A e C) e depois (B e D) da normalização dos dados. A e B referem-se às três repetições obtidas com a variedade resistente (SP82-1176) e C e D referem-se às três repetições obtidas com a variedade suscetível (SP78-4467). Cada retângulo representa uma única membrana.

de isoprenóides incluem pigmentos fotossintéticos (clorofila e carotenóides), hormônios (ácido abscisico (ABA), giberelinas (GA), citoquininas, componentes estruturais de membranas (fitoesteróides) e agentes antimicrobianos as fitoalexinas (19).

Os isoprenóides são derivados por uma condensação consecutiva de precursores com 5 carbonos, o isopentenil difosfato (IPP), e seus isômeros dimetilalil difosfato (DMAPP). Vários trabalhos têm demonstrado que, em plantas, duas vias distintas sintetizam IPP. Como os isoprenóides são compostos essenciais, muitos trabalhos têm sido desenvolvidos para o conhecimento da via que inicia sua produção. Todos os isoprenóides são derivados da molécula precursora IPP e DMAPP, que são produzidas em plantas pela via MVA (acetato/ mevalonato) citoplasmática ou pela via MEP plastídica (assim denominada com base no nome da primeira molécula formada nessa via, 2C-metil-D-eritol 4-fosfato) (23). Existem isoprenóides que são sintetizados a um nível muito baixo e agem como hormônios, e há outros isoprenóides que são necessários em grande quantidade, tal como clorofila e carotenóides (43).

As análises indicaram, também, que na variedade resistente ocorre um aumento na expressão de duas outras ESTs, uma com similaridade à proteína LRR transmembrânica e outra com similaridade a proteína com "ziper"de leucina . A EST com similaridade a proteína quinase transmembrânica com repetições ricas em leucina (LRR) (LR1108D11, e-vale: 2e-09, gi:15241089), atuam no reconhecimento de moléculas elicitoras liberadas pelo patógeno. O gene Xa21 codifica uma proteína com 1025 aa, que possui um peptídeo sinal, 23 LRRs extracitoplasmáticos com numerosos sítios potenciais de glicolisação, um domínio transmembrânico e um domínio quinase entracelular (17), sugerindo que o caminho de transdução de sinais é baseado em uma interação proteína/proteína e fosforilação/desfosforilação (41). Considerando que Xanthomonas oryzae pv oryzae coloniza, preferencialmente, os vasos do xilema, assim como Xanthomonas albilineans, aumentam os indícios de que a EST LR1108D11 esteja envolvida no processo de resistência a escaldadura da folha em cana-de-açúcar (Figura 6). A outra EST induzida apresentou similaridade a proteína contendo "ziper de leucina (LZ) (LR1003D10 e-value: 1e-12, gi:50947893). Estes dois domínios, LRR e LZ, tem sido encontrados em grande parte dos genes $R$ clonados até a presente data. Domínios tipo LZ podem mediar a interação entre proteínas, como por exemplo, a interação entre as proteínas Avr (patógeno) e proteínas R (planta) (4).

Uma EST com similaridade a uma provável proteína mutase/ prefenato dehidratase (LR1087G09,e-value: 5.e-49, gi:37536214) foi superexpressa na variedade resistente. Em Arabdopsis foi clonado e caracterizado um gene que codifica a enzima corismato mutase que cataliza a primeira etapa na síntese de fenilalanina e tirosina (29). 

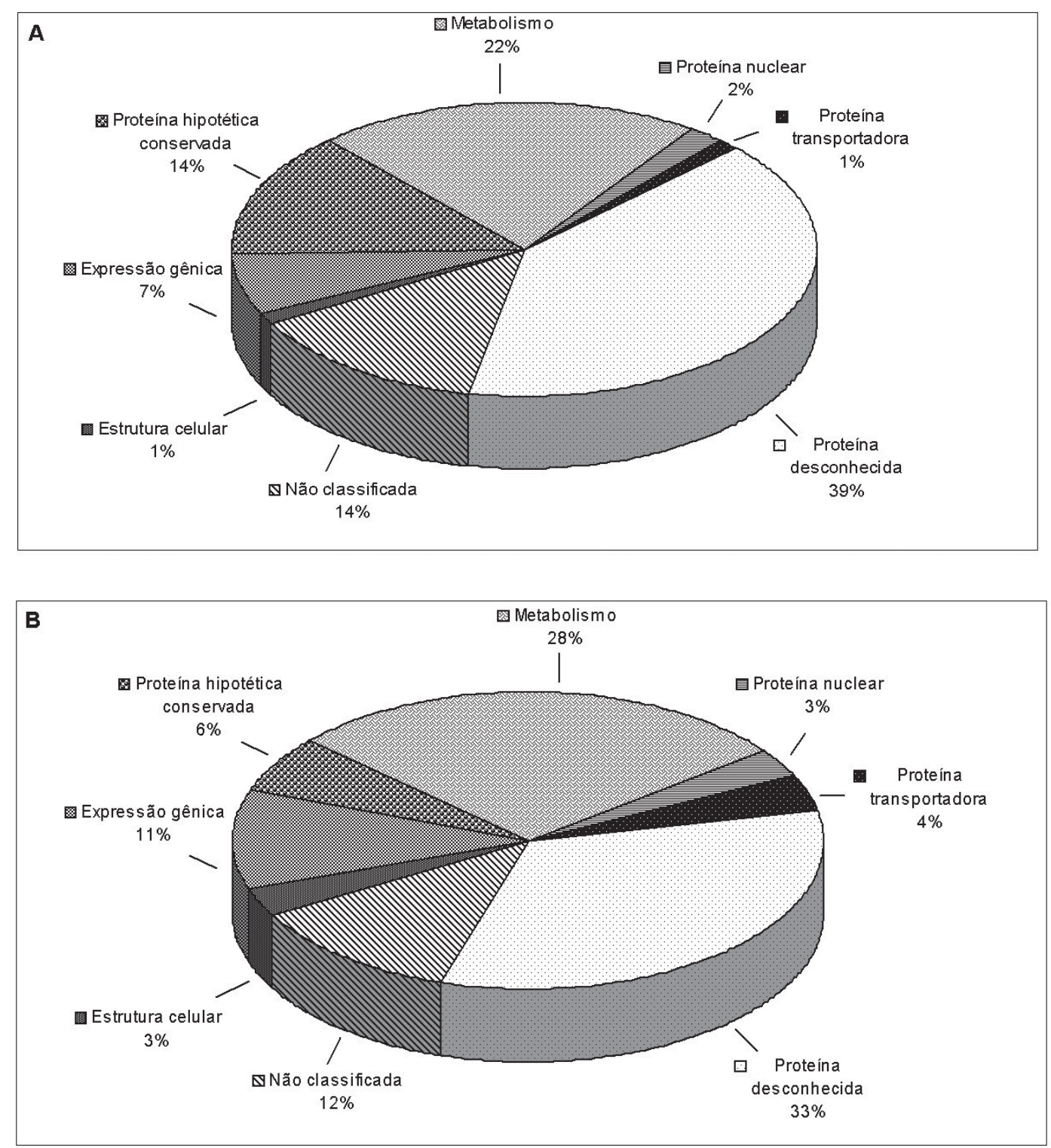

Figura 3. Classificação funcional das 100 ESTs diferencialmente expressas em cada variedade.(A) distribuição funcional das ESTS diferencialmente expressas na variedade resistente (SP82-1176), e em (B) na variedade suscetível (SP78-4467) de cana-de-açúcar na interação com X. albinineans

Aminoácidos aromáticos como fenilalanina, tirosina e triptofano, são requeridos para biossíntese de proteínas e precursores de metabólitos aromáticos secundários, incluindo o hormônio auxina, que é um regulador de crescimento da planta (3-indol-ácido acético), alcalóides antimicrobianos, flavanóides, e compostos polifenólicos tais como as ligninas que são requeridas para a estrutura do xilema $(20,22,31)$. Segundo Hilaire 2001 (18), a lignificação da parede celular está relacionada ao mecanismo de defesa da planta durante a interação planta-patogeno. $\mathrm{O}$ engrossamento da parede secundária do xilema diminui a extensão da membrana que é exposta às células bacterianas, reduzindo o acesso das células ao xilema parenquimático. Logo, paredes lignificadas no vaso do xilema podem funcionar como uma barreira à transferência de compostos produzidos pela bactéria para a célula vegetal, como fatores de virulência e avirulência (18) (Figura 6).

Uma EST com similaridade à glutationa sintetase (LV1048B10, evalue: 3.e-33, gi:50428521) apresentou-se reprimida na variedade resistente. A glutationa é sintetizada a partir da glutationa sintetase, sendo a principal responsável pela proteção de plantas contra espécies reativas de oxigênio (peróxido de hidrogênio, radicais hidroxila, ânion superóxido) produzidas durante estresse bióticos e abióticos. Uma das respostas de defesa mais rápida empregando o reconhecimento do patógeno é a explosão oxidativa, a qual compreende a produção de espécies intermédiarias reativas de oxigênio primeiramente superóxido e peróxido de hidrogênio, no local da invasão do patógeno (2). Peróxido de hidrogênio é um oxidante estável (38), apresentando capacidade de atravessar facilmente a camada bilipídica da membrana celular e promover a rápida elicitação da resposta do vegetal ao estresse (1). Dentre as várias funções no apoplasto da célula hospedeira, o peróxido de hidrogênio possui ação antimicrobiana, é precursor na cascata de transdução de sinais para ativação de genes de defesa, (32), e evidências indicam seu envolvimento em muitos mecanismos de resistência da planta a estresse, participando da via de lignificação a qual forma uma 


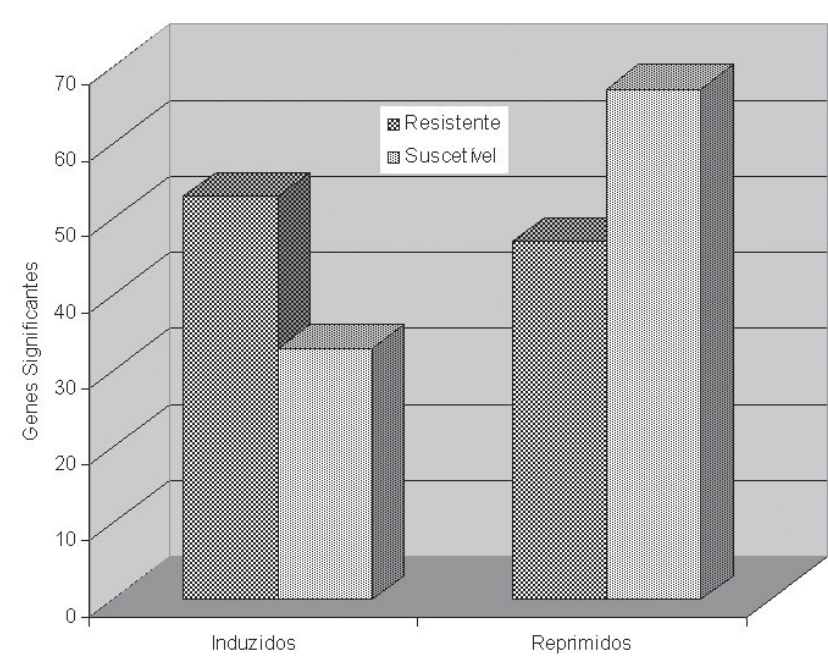

Figura 4: Perfil de indução e de repressão dos 100 ESTs mais significativos estatisticamente de cada variedade de cana-de-açúcar. $\mathrm{Na}$ variedade resistente (SP82-1176), 53 genes foram induzidos e 47 reprimidos; na variedade suscetível (SP78-4467) 33 genes foram induzidos e 67 reprimidos.
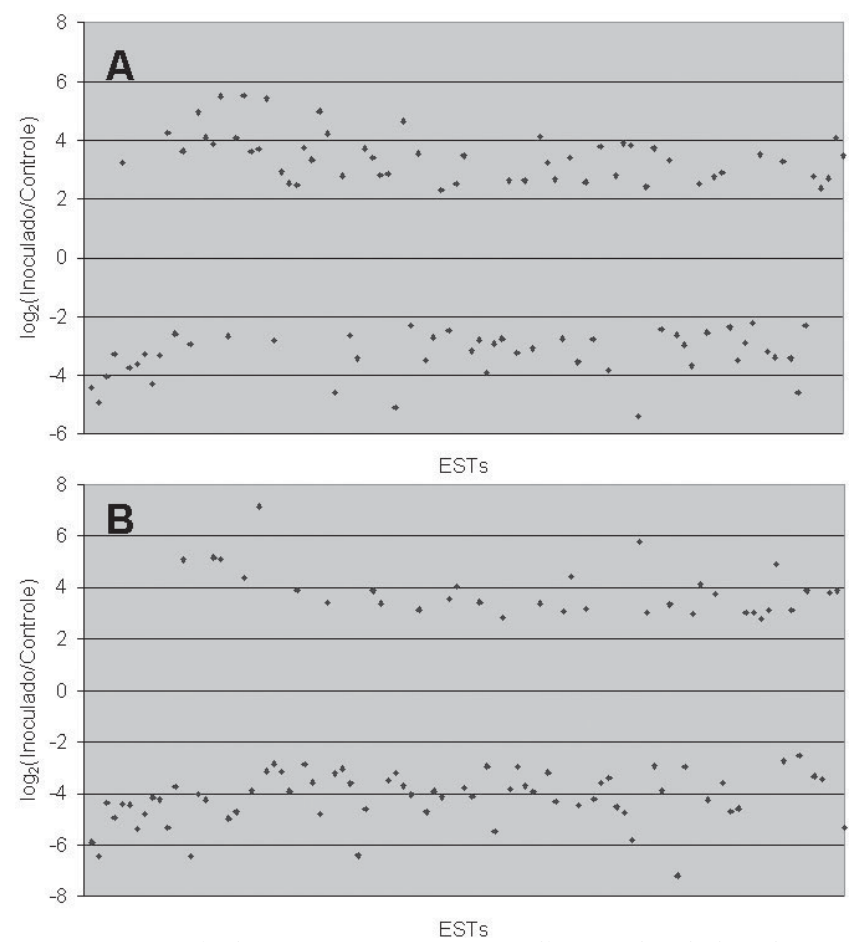

Figura 5. Níveis de expressão, após normalização dos dados, dos 100 ESTs mais significativos estatisticamente. Na parte inferior do gráfico, abaixo do zero, são mostrados os respectivos níveis para os ESTs reprimidos e na parte superior são apresentados os induzidos. (A) ESTs da variedade resistente; (B) ESTs da variedade suscetível.

barreira mecânica bloqueando fisicamente a propagação do patógeno (47). Estudos realizados por El-Zahaby, 2004 (15) indicam que os radicais superoxidase e o peróxido de hidrogênio eram os mais importantes envolvidos na explosão oxidativa resultando na inibição do crescimento do patógneo na planta e alteravam os sintomas no tabaco. Segundo Coego et al (2005) (9), a inibição da expressão do gene Ep $5 C$, o qual codifica uma peroxidase catiônica, é suficiente para conferir resistência contra Pseudomonas syringae pv tomato. A expressão do gene Ep5C é rapidamente induzida por peróxido de hidrogênio, que é uma espécie reativa de oxigênio, normalmente gerada durante a interação planta-patógeno. Segundo o mesmo autor (9), a redução do crescimento do patógeno pode ser considerada uma nova forma de resistência à doença baseada na perda da habilidade do hospedeiro em manter o patógeno, a qual age independentemente da resistência mediada pelo gene $\mathrm{R}$ ou da ativação de defesas do hospedeiro, ou seja, trata-se de uma resistência de amplo espectro. O fato da EST, que possui homologia com uma glutationa sintetase (LV1048B10 evalue 3.e-33, gi:50428521), ter sido reprimida na variedade resistente após inoculação com $X$. albilineans está de acordo com os estudos anteriores discutidos, ou seja, a diminuição de glutationa leva ao acúmulo de espécies reativas de oxigênio controlando, desta maneira, a proliferação bacteriana, e por sua vez, os sintomas característicos da doença não são elicitados (Figura 6).

Uma EST associada a senescência (LR1131C02, e-value: 3 e-59, gi:12836895) foi reprimida na variedade resistente. A senescência pode facilitar o desenvolvimento de doenças causadas por patógenos, principalmente necrotróficos (25). A planta resistente, mantendo reprimido esse gene, poderia retardar a ação de bactérias necrotróficas. Por outro lado, as plantas suscetíveis poderiam induzir a senescência de um órgão infectado por um patógeno a fim de controlar a doença.

Foi reprimida na variedade suscetível uma EST com similaridade a pró-enzima S-adenosilmetionina descarboxilase (AdometDC) (LR2014E11, e-value: 0, gi:3913427), a qual está relacionada com a síntese de etileno. O composto precursor do etileno é o S-adenosil metionina (AdoMet) que forma 1-aminociclopropano-1-ácido carboxilico (ACC) que é posteriormente convertido em etileno, $\mathrm{CO}_{2}$, e $\mathrm{HCN}$ pela ACC oxidase. Vários estudos têm revelado impressionante similaridade entre respostas ao estresse biótico e senescência (30), ferimentos (35) e estresse à seca (21). O hormônio vegetal etileno é um importante sinal em muitas situações de estresse abiótico, mas também em interações planta-patógeno (8). Talvez os genes relacionados a senescência e a síntese de etileno sejam reprimidos em ambas as variedade, devido a fatores produzidos pelo patógeno que na variedade resistente inibe a senescencia mas não inibe a resistência, a qual é obtida por outras vias metabólicas.

Uma EST codificando uma provável proteína fosfatase (LR2031E06, e-value: e-138, gi:9909177) também apresentou-se reprimida na variedade suscetível. Moléculas sinais geradas no sítio de infecção durante interação planta-patógeno podem induzir resposta de defesa sistemicamente. Tem sido mostrado que o reconhecimento de vários sinais microbianos é mediado por receptores transmembrânicos do tipo quinase e induzem a cascata de eventos fosforilação/desfosforilação resultando finalmente na ativação/ repressão de genes relacionados à resposta de defesa da planta (26).

Nossos resultados mostraram o mesmo clone (LR1058A08, evalue: 8.e-51, gi:34913856) com similaridade a RNA helicase, apresentando-se induzido na variedade resistente e reprimido na suscetível (Figura 6), mostrando assim um comportamento diferenciado para cada variedade durante $o$ ataque do patógeno cuja expressão pode estar relacionada com a diferenciação de plastídeos e a tolerância ao frio. Existem helicases que pertencem à família DEAD “box' presente em procariotos e eucariotos e tem um importante papel póstranscricional, no crescimento e na diferenciação celular (11). Um possível papel desta RNA helicase na diferenciação de plastídeos e desenvolvimento da planta tem sido proposto, sendo a mesma 

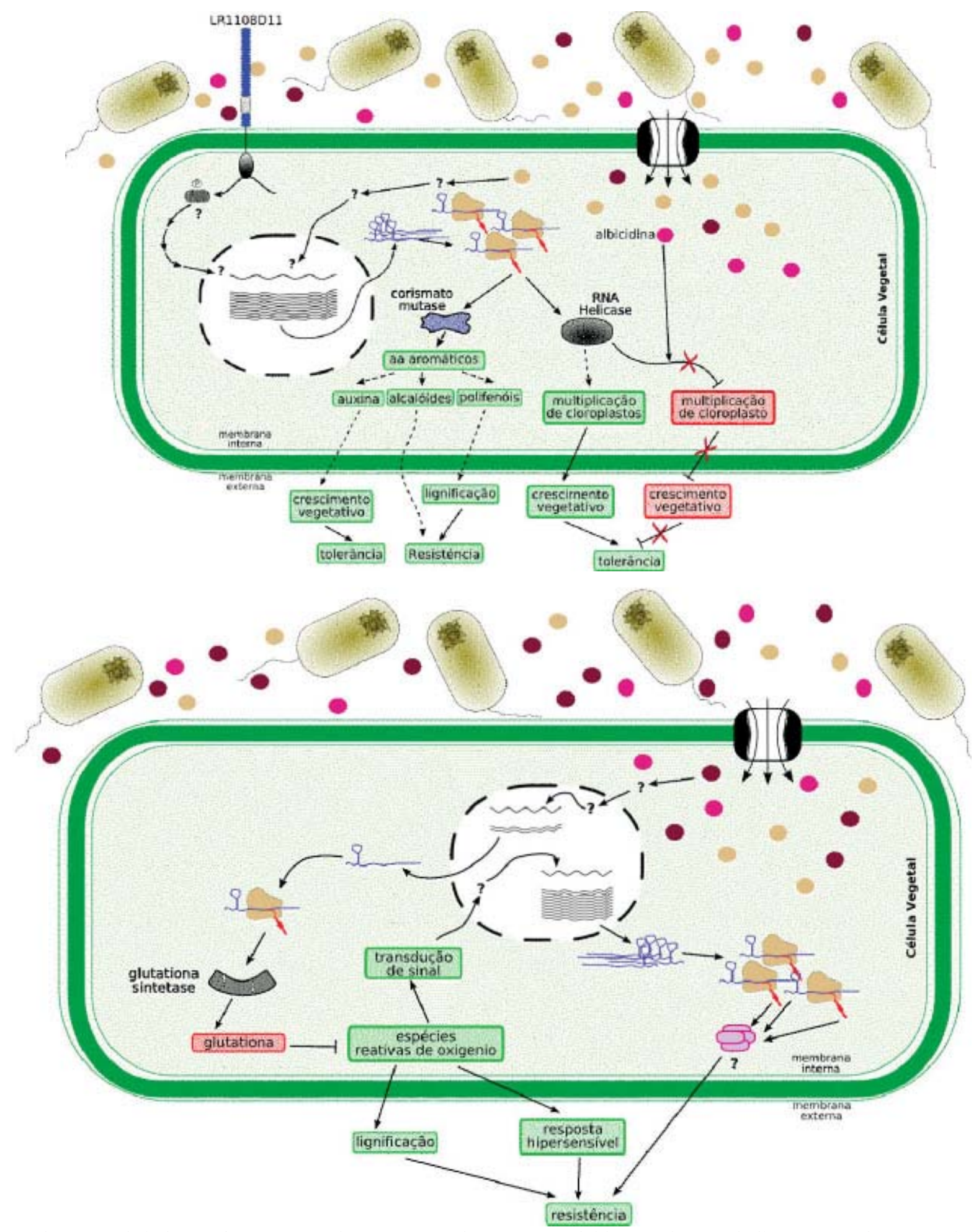

Figura 6. Ilustração de indução e/ou repressão de ESTs que podem estar envolvidas em vias metabólicas que resultam na resistencia ou suscetibilide de cana-de-açúcar quando submetida ao estresse biótico com X. albilineans. (A) indução das ESTs similar a Corismato Mutase e RNA Helicase, na variedade resistente, e que estão envolvivas com fatores de resistencia e repressão a mesma EST com similaridade a RNA Helicase na variedade suscetível. (B) Repressão da EST com similaridade glutationa que por sua vez induz a ativação de outras vias que conferem resistência.

relacionada com o desenvolvimento de cloroplastos e morfogênese foliar (20). Os cloroplastos são considerados o principal tipo de plastídeo, não realizando apenas fotossíntese, mas também outros processos metabólicos, como síntese de lipídeos, aminoácidos e hormônios. O desenvolvimento de cloroplastos a partir de protoplastídeos não diferenciados ocorre por meio de uma série de 
processos biológicos envolvendo um grande número de proteínas (44). Muitas evidências indicam que o desenvolvimento dos cloroplastos regula a diferenciação foliar, especialmente a morfogênese do mesófilo (27).

Em tabaco, a mutação do gene $v d l$ (variegated and distorted leaf) foi identificada dentro de um locus que presumivelmente codifica uma RNA helicase de cloroplasto. A identificação de uma inserção T-DNA neste gene afeta o desenvolvimento de folhas, flores e raíz (20). O locus VDL codifica uma provável RNA helicase pertencente à superfamília DEAD “box" (20). A observação de que VDL é expressa em tecidos não-fotossintéticos e que sua interrupção afeta raízes e flores indica que a mesma está envolvida, também, na diferenciação de todos os plastídeos de diferentes tecidos vegetais (42). Em Arabidopsis thaliana, proteína tipo RNA helicase foi associada a fatores de transcrição relacionados a tolerância ao frio e ao congelamento (16). A toxina albicidina, produzida pela bactéria causadora da escaldadura da folha, em variedades suscetíveis, inibe o desenvolvimento dos cloroplastos, alterando suas funções (6) (Figura 6). A indução diferencial da enzima helicase na variedade resistente talvez seja um dos fatores que confere resistência à doença causada por $X$. Albilineans ou sua repressão pode causar suscetibilidade.

Foi reprimida na variedade suscetível uma EST com similaridade a proteína contendo motivo do tipo dedos de zinco "zinc finger-tipo C3HC4" (LR1051C03, e-value: 1.e-11, gi:15227929). Entre os genes identificados por mutagênese, em Arabidopsis thaliana, LSD1 codifica um regulador negativo de PCD (morte programada da célula) de planta. A proteína codificada por LSD1 contém três "zinc finger" altamente relacionados e pode funcionar como reguladora de transcrição ou como uma proteína relacionada com estrutura (13).

É interessante ressaltar que tanto na variedade resistente quanto na suscetível foi reprimida uma EST com similaridade ao carreador da auxina (LR1069F12, e-value: e-41, gi:18409758), que são considerados transportadores de influxo e efluxo responsáveis pela concentração de auxina nas células. A auxina é transportada através da membrana plasmática das células de planta por difusão e por transportadores que atuam em direções opostas: transportadores de influxo e efluxo. Os dois transportadores provavelmente têm um papel importante, controlando a concentração de auxina e sua distribuição na planta (12). O transporte de auxina é essencial em vários estágios de desenvolvimento da planta, para garantir um crescimento coordenado a nível celular e fornecer a capacidade para responder a estímulos ambientais (24). Provavelmente, na variedade resistente outra enzima poderá estar desenvolvendo este papel.

As seqüências de aminoácidos dos genes com similaridade a proteínas hipotéticas e desconhecidas podem ser analisadas para se determinar a presença de domínios protéicos característicos e, desta maneira, inferir possíveis funções para as mesmas. Além disso, estes genes podem ser investigados por meio da técnica de duplo-híbrido, com o intuito de identificar possíveis interações com outras proteínas de funções conhecidas.

Com base nos nossos dados podemos observar a diferença na expressão gênica entre as duas variedades de cana-de-açúcar quando submetidas a estresse biótico com $X$. albilineans. Os resultados obtidos mostram que o perfil de resistência pode estar relacionado principalmente com o controle do crescimento da bactéria na planta e a indução e repressão de vias metabólicas envolvidas com a resistência, como pode-se observar na variedade de cana-de-açúcar resistente a escaldadura e repressão de vias na variedade suscetível (Figura: 6)

\section{Agradecimentos}

O presente trabalho foi realizado com auxílio financeiro da FAPESP (Proc.00/02179-8) e do CNPq (Proc.521190/96-7) e cooperação do Centro de Tecnologia Canavieira (CTC).

\section{Referências Bibliográficas}

1. Apostol, I., Heinstein, F.H.; Low, P.S. Rapid stimulation of an oxidative burst during elicitation of cultured plant cells. Rolle in defense and signal transduction. Plant Physiology, Rockville, v. 90, n. 1, p. 109-116, 1989.

2. Baker, C.J.; Orlandi, E.W. Active oxygen species in plant pathogenesis. Annual Reviews Phytopathology, Palo Alto, v.33, p. 299321, 1995.

3. Benjamini, Y.; Hochberg, Y. Controlling the false discovery rate: a practical and powerful approach to multiple testing. Journal of the Royal Statistical Society Series B v.57, p.289-300, 1995.

4. Bent, A. F. Plant disease resistance genes: function meets structure. The Plant Cell, Rockville v. 8, n.10, p.1757-1771, 1996.

5. Birch, R. G.; Patil, S. S. Evidence that an albicidin-like phytotoxin induces chlorosis in sugarcane leaf scald disease by blocking plastid DNA replication. Physiological and Molecular Plant Pathology, Oxford, v.30, n.2, p. 207-214, 1987.

6. Birch, R. G.; Patil, S.S. Preliminary characterization of an antibiotic produced by Xanthomonas albilineans which inhibits DNA synthesis in Escherichia coli. Journal of General Microbiology, v.131, n.5, p. 1069-1075, 1985.

7. Birch, R. G.; S. S. Patil. 1987. Correlation between albicidin production and chlorosis induction by Xanthomonas albilineans, the sugarcane leaf scald pathogen. Physiological and Molecular Plant Pathology, Oxford, v.30, n.2, p. 199-206, 1987.

8. Boller T. Ethylene in pathogenesis and disease resistance. In: Matoo, A. K.; Suttle, J.C., (Ed.), The plant hormone ethyelene. Boca Raton:CRC Press, 1991.p 293-314.

9. Coego, A.; Ramirez, V.; Ellul, P.; Mayda, E.; Vera P. The H O regulated Ep5C gene encodes a peroxidase required for bacterial speck susceptibility in tomato. The Plant Journal, Oxford,v. 42, n.2, p.283-293, 2005.

10. Comstock, J.C.; Irey, M.S. Detection of the sugarcane leaf scald pathogen, Xanthomonas albilineans, using tissue blot immunoassay, ELISA, and isolation techniques. Plant Disease, v.76, p. 10331035, 1992.

11. De la Cruz, J.; Kressler, D.; Linder, P. Unwinding RNA in Saccharomyces cerevisiae $\mathrm{DEAD}$-box proteins and related families. Trends in Biochemical Sciences. London, v.24, n.5, p.192-198, 1999.

12. Delbarre, A.; Muller, P.; Imhoff, V.; Morgat, J. 1.; Barbier-Brygoo, H. Uptake, accumulation and metabolism of auxins in tobacco leaf protoplasts. Planta, New York, v.195, n.2, p.159-167, 1994.

13. Dietrich, R. A.; Richberg, M. H.; Schimidt, R.; Dean, C.; Dangl, J. $\mathrm{L}$. A novel zinc finger protein is encoded by the arabidopsis LSD1 gene and functions as a negative regulator of plant cell death. Cell. Cambridge, v. 88, n.5, p. 685-694, 1997.

14. Dudoit, S.; Yang, Y. H. Bioconductor R packages for exploratory analysis and normalization of cDNA microarray data. In: Parmigiani G.; Garrett, E. S.; Irizarry, R. A.; Zeger, S. L. (Ed.), The analysis of gene expression data: methods and software. New York: Springer, 2002

15. El-Zahaby, H. M.; Hafez, Y. M.; Király, Z. Effect of Reactive Oxygen Species on Plant Pathogens in plant and on Disease Symptoms. Acta Phytopathologica et Entomologica Hungarica, v. 39, n. 4, p. 325-345, 2004 
16. Gong, Z.; Lee, H.; Xiong, L.; Jagendorf, A.; Stevenson, B.; Zhu, J.K. RNA helicase-like protein as an early regulator of transcription factors for plant chilling and freezing tolerance. Proceedings of the National Academy of Sciences, New York, v.99, n.17, p.11507-11512, 2002.

17. Hammond-Kosack, K. E.; Jones, J. D. G. Plant disease resistance genes. Annual Reviews Plant Physiology Plant Molecular Biology, Palo Alto, v.48, n.1, p.575-607, 1997.

18. Hilaire, E.; Yong, S.A.; Willard, L.H.; McGee, J.D., Sweat, T.; Chittoor, J.M., guikema, J.A.; Leach, J. E. Vascular defense responses in rice: peroxidase accumulation in xylem parenchyma cells and xylem wall thickening. Molecular Plant-Microbe Interactions, St. Paul, v.14, n.12, p.1411-1419, 2001

19. Hirschberg, J. Production of high-value compounds: carotenoids and vitamin E. Current Opinion in Biotechnology, London, v.10, n.2, p.186-191, 1999

20. Keddie, J. S.; Carroll, B.; Jones, J. D. G.; Gruissem, W. The DCL gene of tomato is required for chloroplast development and palisade cell morphogenesis in leaves. The EMBO Journal, Heidelberg, v.15, n.16, p. 4208-4217, 1996.

21. Langenkamper. G.; Manac'h, N.; Broin, M.; Cuiné, S.; Becuwe, N.; Kuntz, M.; Rey, P. Accumulation of plastid lipid-associated proteins (fibrillin/CDSP34) upon oxidative stress, ageing and biotic stress in Solanaceae and in response to drought in other species. Journal of Experimental Botany, Oxford, v.52, n.360, p.15451554, 2001.

22. Lewis, N. G., Yamamoto, E. Lignin: occurrence, biogenesis and biodegradation. Annual Review of Plant Physiology Plant Molecular Biology, v.41, p.455-496, 1990.

23. Lichtenthaler, H. K.; Rohmer, M.; Schwender, J. Two independent biochemical pathways for isopentenyl diphosphate and isoprenoid biosynthesis in higher plants. Plant Physiology, Rockville, v.101, n.3, p. 643-652, 1997.

24. Lomax, T. L.; Muday, G. K.; Rubery, P. H. Auxin transport. In: Davies P. (Ed.) Plant hormones: physiology, biochemistry and molecular biology. $2^{\text {nd }}$ ed. Boston: Kluwer Academic Publishers p. 509-530,1995.

25. Lund, S. T.; Stall, R. E.; Klee, H. J. Ethylene regulates the susceptible response to pathogen infection in tomato. The Plant Cell, Rockville, v.10, n.3, p. 371-382, 1998.

26. Mac Dowell, J. M.; Dangl, J. L. Signal transduction in the plant imune response. Trends in Biochemical Sciences. London, v.25, n.2, p.79-82, 2000.

27. Mandel, M. A.; Feldmann, K. A.; Herrera-Estrella, L.; Rocha-Sosa, M.; Leon, P. CLA1, a novel gene required for chloroplast development, is highly conserved in evolution. The Plant Journal, Oxford, v.9, n.5, p.649-658, 1996.

28. McPherson, J.D. Overgo Probing of High-Density Filters. 2000. Disponível em: http://www.tree.caltech.edu/protocols/ overgo.html McQueen-Mason, S.; Cosgrove, D. J. Disruption of hydrogen bonding between plant cell wall polymers by proteins that induce wall extension. Proceedings of the National Academy of Sciences of the United States of America, New York, v.91, n.14, p. 6574-6578, 1994.

29. Mobley, E. M., Kunkel, B. N., Keith, B. Identification characterization and comparative analysis of a novel chorismate mutase gene in Arabidopsis thaliana. Gene, Napoli, v. 240, n.1, p.115-123, 1999.

30. Ogawa, K.; Kanematsu, S.; Asada, K. Generation of superoxide anion and localization of $\mathrm{Cu} \mathrm{Zn}$-superoxide dismutase in the vascu- lar tissue of spinach hypocotyls: their association with lignification. Plant Cell Physiology, Oxford, v.38, n.10, p.1118-1126, 1997.

31. Radwanski, E. R., Last, R. L. Tryptophan biosynthesis and metabolism: biochemical and molecular genetics. The Plant Cell, Rockville, v.7, n7, p.921-934, 1995.

32. Resende, V.L.M.; Salgado L.M. S.; Chaves, M.Z. Espécies ativas de oxigênio na resposta de defesa de plantas a patógenos. Fitopatologia Brasileira, Brasília, v. 28, n.2, p.123-130, 2003.

33. Ricaud, C., Ryan, C. C. Leaf scald. Pages 39-58 in: Diseases of Sugarcane. C. Ricaud, B.T. Ryan, A.G. Gillaspie, Jr. and C.G. Hughes, eds. Elsevier Publishing Co., Amsterdam, 1989.

34. Riechmann, J.L.; Heard, J.; Martin, G.; Reuber, L.; Jiang, C.; Keddie, J.; Adam, L.; Pineda, O.; Ratcliffe, O.J.; Samaha, R.R.; Creelman, R.; Pilgrim, M.; Broun, P.; Zhang, J.Z.; Ghandehari, D.; Sherman, B.K.; Yu, G. Arabidopsis transcription factors: Genome-wide comparative analysis among eukaryotes. Science, Washington, v.290, n.5499, p.2105-2110, 2000.

35. Romeis, T.; Piedras, P.; Zhang, S. Q.; Klessig, D. F.; Hirt, H.; Jones, J. D. G. Rapid Avr-9 and Cf-9-dependent activation of map quinases in tobacco cell cultures and leaves:convergence of resistance gene, elicitor, wound, and salicylate responses. The Plant Cell, Rockville v.11, n.2, p.273-287, 1999.

36. Rott, P., Chagvardieff, P. In vitro reactions of sugarcane (Saccharum SP.) plantles inoculated with 2 strains of Xanthomonas albilineans (Ashby) Dowson. Plant Cell,Tissue and Organ Culture, Netherlands, v. 9, p. 9-18, 1987.

37. Sambrook, J.; Fritsch, E.F.; Maniatis, T. Molecular Cloning: a laboratory manual. $2^{\text {nd }}$ edition. Cold Spring Harbor, NY:Cold Spring Harbor Laboratory Press, 1989.

38. Schopfer P. Hydroxyl radical-induced cell-wall loosening in vitro and in vivo: implications for the control of elongation growth. Plant Journal, Oxford v.28, n.6 p.679-688, 2001.

39. Schummer, M.; Ng. W. V.; Bumgamer, R.E.; Nelson, P.S.; Schummer, B.; Bednarski, D.W.; Hassell, L.; Baldwin, R.L.; Karlan, B.Y.; Hood, L. Comparative hybridization of an array of 21500 ovarian cDNAs for the discovery of genes overexpressed in ovarian carcinomas. Gene, Napoli, v.238, p.375-385, 1999.

40. Smyth, G.K.; Yang, Y.H.; Speed, T.P. Statistical issues in microarray data analysis. In: Brownstein, M.J; Khodursky, A.B. (Ed.) Functional genomics: methods and protocols. Totowa: Humana Press, 2003. p.111-136. Methods in molecular biology, v.224.

41. Staskawicz, B.J.; Ausubel, F.M.; Baker, B.J.; Ellis, J.G., Jones, J.D. Molecular genetics of plant disease resistance. Science, Washington, v.268, n.5211, p.661-7,1995.

42. Stern. D.; Higgs. D.; Yang. J. Transcription and translation in chloroplasts. Trends in Plant Science, London, v.2, n.8, p.308-315, 1997.

43. Stévez, J.; Araceli, C.; Reindl, A.; Stuart, R.; León, P. 1- Deoxy-Dxylulose-5-phosphatase synthase, a limiting enzyme for plastidic isoprenoid biosynthesis in plants. The Journal of Biological Chemistry, Bethesda, v.276, n.25, p.22901-22909, 2001.

44. Surpin, M.; Chory, J. The co-ordination of nuclear and organellar genome expression in eukariotic cells. Essays in Biochemistry, London, v.32, p.113-125, 1997.

45. Vettore, A.L., Silvva, S.R., Kemper, E.L., Arruda, P. The libraries that made SUCEST. Genetics and Molecular Biology, v. 24, n.1, p.1-7, 2001.

46. Yang, Y. H.; Dudoit, S.; Luu, P.; Lin, D. M.; Peng, V.; Ngai, J.; Speed, T. P. Normalization for cDNA microarray data: a ro- 
bust composite method addressing single and multiple slide systematic variation. Nucleic Acids Research, Oxford, v.30, n. 4 e 15, p.1-10, 2002.

47. Young, S. A., Guo, A., Guikema, J. A., White, F.F., Leach,
J. E. Rice cationic peroxidase accumulates in xylem vessels during incompatible interactions with Xanthomonas oryzae pv. oryzae. Plant Physiology, Rockville, v.107, n.4, p.1333-1341, 1995 